\title{
Neuro- Psychological Assessment of the Suspect by Applying Brain Electrical Oscillation Signature (BEOS) Profiling Test to Verify BEOS Principle
}

\author{
Mr. Patel Anjan. $\mathrm{N}^{1} *$
}

\section{ABSTRACT}

Neuro-psychological assessment of the suspect by applying Brain electrical oscillation signature profiling (Brain mapping)test to verify BEOS principle. BEOS test is applicable in forensic field for detection of a person as suspect, accused, witness or complainant.

BEOS is based on EEG and its principle is neuro-psychology. Neuro-psychological criteria of BEOS system contains Experiential Knowledge (EK), Primary processing (PP), Encoding (EN), Emotional Response (ER), Activation Suppression (AS), Inattention (IN) ; etc. "32" electrodes EEG cap to be attached to a suspect and REM electrodes for rotatory eyes moment to be attached. An EEG gel to be fill for better conductivity.

Civil and criminal cases examined on BEOS system. As per NHRC guidelines a person willingly gave written consent to undergo for BEOS test as well as person's jurisdictional court order to conduct a BEOS test is mandatory. Case related audio-visual pre-recorded probes presented to the suspect. Probes framed as neutral, general neutral and relevant point of view. A suspect has to seat in isolated room and he need not to give answer to the presented probes. "Right to remain silent" these constitutional rights are safe for suspect.

BEOS system does automatic EEG analysis and generates result in the form of Experiential Knowledge, Primary processing, Encoding, Emotional Response, Activation Suppression, Inattention.

Around 1420 sample of probes taken for neuro-psychological assessment. U/s: 302 of IPC's real cases were taken and four person examined. Changes in the different frequency bands have different meaning in terms of cognitive and neuro psychological processing. In all four person's BEOS automated result, i found Experiential Knowledge, Primary processing, Encoding,

\footnotetext{
${ }^{1}$ Scientific assistant, Directorate of Forensic Sciences, Government of Gujarat; Research scholar Rai University, Dholka ,Saroda, Ahmedabad

*Responding Author

(C) 2016 I A Patel; licensee IJIP. This is an Open Access Research distributed under the terms of the Creative Commons Attribution License (http://creativecommons.org/licenses/by/2.0), which permits unrestricted use, distribution, and reproduction in any Medium, provided the original work is properly cited.
} 


\section{Neuro- Psychological Assessment of the Suspect by Applying Brain Electrical Oscillation Signature (BEOS) Profiling Test to Verify BEOS Principle}

Emotional Response, Activation Suppression, Inattention shows different sum of digits. On that bases my first hypothesis depict wrong because BEOS is not analyzing total result. Result depends on person's fact of story and his involvement in the offense and these makes difference in the result of EK, PP, EN, ER, A Supp, and Inattention.

Sum of four person's result percentile shows above 95\% suspect was aware during the BEOS test, so my second hypothesis "BEOS principle is neuro-psychology, it is baseless principle; which Ho is rejected because suspect was neuro-psychologically aware during BEOS test so that their results of EK, PP, EN, ER, A Supp, Inattention counted different values as per their involvement.

NABL Scope of Accreditation report mentioned that BEOS test is for verification of veracity of statement of the suspect, accused, witness, complainant and victim. BEOS instrument's range of testing and limits of detection is .99 (200). These research supports NABL scope report of BEOS range testing limits and makes confirmation that BEOS principle is neuro-psychology which is true.

Keywords: Neuro-Psychology, Brain Electrical oscillation, Brain mapping, BEOS principle.

Researcher applied (BEOS) Brain electrical oscillation signature profiling technique to analyze person's neuro-psychological awareness during the examination. In this research two cases and four person were examined. As per NHRC guideline all the four person willingly gave their written consent to undergo for BEOS test. Visual and audio probes were present as stimulation to the suspected person seated in a isolated lab. A first probe set contains person's narration and second set of probes remains hypothetical. Criminal and civil cases were examined on BEOS test. BEOS is noninvasive technique. Brain electrical oscillation signature profiling is based on the principles of neuro-psychology.

Researcher want to find out that related probes of suspect case matter makes neuro-psychological evocation or not during BEOS test. Case related probes framed by experts and pre-recorded probes presented to the suspect. Different scenarios are designed based on principles of encoding and retrieval of information. To test these hypotheses, event related items are used as probes designed in a consecutive and chronological manner to evoke the same neuro-psychological state as the perpetrator was in when the event occurred. These scenario and probes are documented as audio probes or data-bank, which is presented to the suspect/subject through a computer, monitored audio system in the brain lab. While suspect is listening to these event related scenario, activation of different areas of the brain is reached by an EEG-ERP system.

The ready-made software is used to derive epoch files for each probe separately. Software also generates readymade results based on statistical analysis. Analysis is carried out by the software program for left and right hemisphere electrodes separately and computed with different 


\section{Neuro- Psychological Assessment of the Suspect by Applying Brain Electrical Oscillation Signature (BEOS) Profiling Test to Verify BEOS Principle}

statistical analysis. Auto analyzed BEOS report taken for data analysis. The change in the power profile in each segment are classified into EK(Experimental Knowledge), EM response, NE response, Encoding present and primary processing present. Changes in the different frequency bands have different meaning in terms of cognitive processing. Software generates the result in the following category for the interpretation from the forensic angle. BEOS result and it's individual count of Experiential Knowledge, Primary processing, Encoding, Emotional Response, Activation Suppression, Inattention are granted for persons neuro-psychological assessment. Percentage counted from total number of probes of each sets elects neuropsychological assessment of person who was aware during whole examination.

Dr. S.L Vaya (2005-2007), Additional Director and Principal investigator of National Resource center, Forensic Psychology DFS Gandhinagar, Gujarat, India. Book referred: Forensic Psychology's National Resource center (2013). In the year of 2003 BEOS system, procedure and it's report was examined for reliability and validity. Reliability and validity of BEOS system also verified by judicial magistrate and legal personal. This book supports experimental research results of BEOS that persons BEOS result based on memory, visual image, cognitive and neuropsychological.

\section{OBJECTIVE OF THE STUDY}

BEOS is noninvasive technique. Brain electrical oscillation signature profiling is based on the principles of neuro-psychology. Researcher objective is to study and compare result of BEOS test to testify principal of BEOS test.

\section{Hypothesis:}

1. There will be no significant difference in neuro-psychological assessment of BEOS result like Experiential Knowledge, Primary processing, Encoding, Emotional Response, Activation Suppression, Inattention.

2. Brain electrical oscillation signature profiling is based on the principles of neuro-psychology, which is baseless principal.

\section{METHOD}

\section{Sampling:}

Samples were collected from DFS Gandhinagar Gujarat, Forensic Psychology Division, two cases and four subjects are taken for research. Prior oral permission of research is taken from concern officers. Around 1420 probes sample framed as per the case and examined on BEOS. This research is not related to particular crime or suspect but it focused suspects' neuropsychological assessment of awareness to particular probes. In this research nobody's feeling is hurt only auto analyzed digit data of BEOS result is taken for research. 


\section{Tools:}

BEOS (Brain electrical Oscillation Signature Profiling) system N.S.S system includes EEG, Head map generator and VASP system taken for probes recording.32 electrodes EEG cap, EEG gel, REM sensors. N.S.S system is interconnected with three computers and Axxonet software.
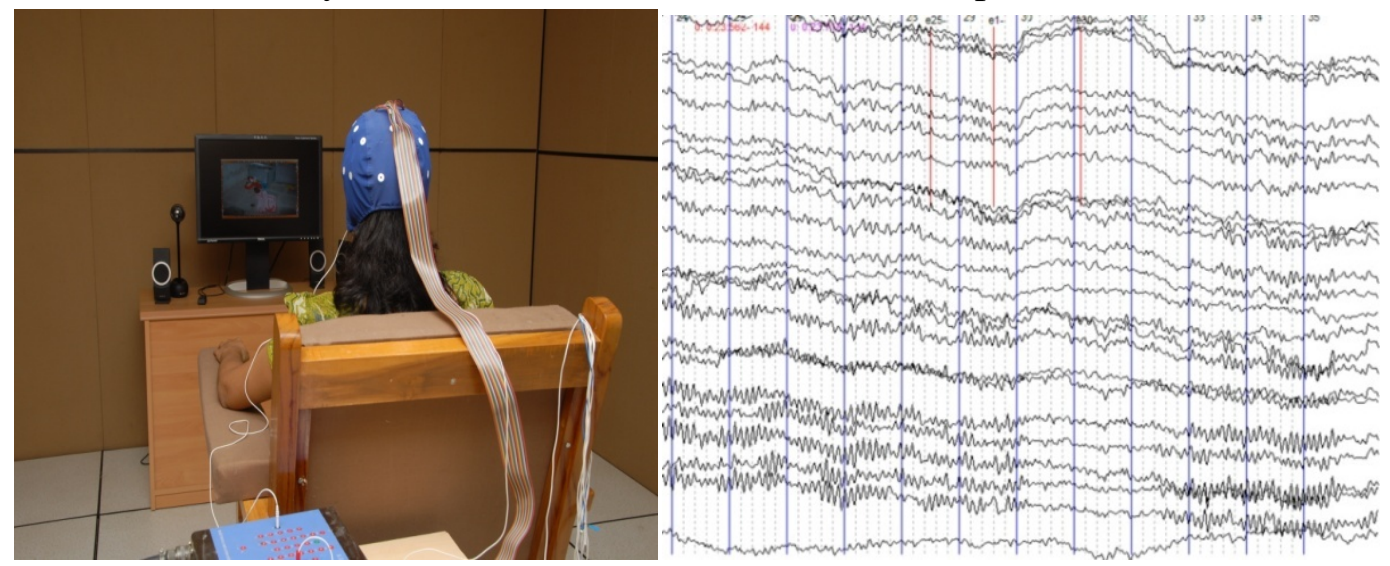

\section{Procedure:}

As per NHRC rules, when person gave written consent then only BEOS test will proceeds. Along with person's consent related jurisdictional court order is mandatory to conduct BEOS test. Under this test reserves the right of the subject to remain silent under Article 20 (3) of the constitution.

In BEOS test a EEG cap attached with 32 electrodes. 32 channels recording of the electrical activity of the brain was carried by placing 30 cephalic electrodes with reference electrodes in the ear lobes, and 2 channels for recording the eye movements. Initially the baseline recording was done with eyes closed and eyes opened. Then neutral probes were presented before presenting crime/event related probes in different scenarios to the subject and the EEG is acquired and analyzed electrical oscillation from the brain were picked up using electrodes placed at standard position such as:

FP1,FP2,AF3,AF4,F7,F3,F8,F4,FT7,FT8,FC3,FC4,T3,T4,C3,C4,TP7,CP3,TP8,CP4,T5,T6,P3,P 4,O1,O2,Fz,Cz and CPz.

The subject has to seat in isolated lab room along. On BEOS test suspect's narration and hypothetical auditory probes and visual probes are presented. The changes in the power profile in each segment are classified into EK(Experimental Knowledge), EM response, NE response, encoding present and primary processing present. Changes in the different frequency bands have different meaning in terms of cognitive and neuro psychological processing. Software generates the result in the category for the interpretation from the forensic angle. 1. Experimental Knowledge(EK): Activity related to remembrance of the experience triggered by the probes present. Presence of significant increase in activation level is the base. 2. Emotional Response (EM): Encoding present accompanied by overwhelming blanking of further 
processing. Probe has produced significant decrease (presence of high level of Desynchronization) in the activity of delta, theta, alpha, beta, gamma bands or no change in the activation level in the above bands, during and after probe presentation. The response is an indication of emotional stunning on hearing the probe. 3. Negative Response (NE): Probes had produced negative response equivalent N400. NE values are above 100 micro volts, it is treated as artifact. 4. Encoding (En): this is used when the probes has produced significant increase in activation in the delta, beta, gamma bands but without increase in $0-2 \mathrm{~Hz}$ activity. 5. Primary Processing (PP): This is used when the probes had produced significant increase in activity only in the beta bands. 6. Inattention (In): Activity related to registration of the probe is not detected.

On presentation of the probes, graph being generated and EK is elicited. BEOS is applicable in cases, wherein major offenses and some evidence is available. Later BEOS test result like experiential knowledge is elicited from the subject about the crime. The result is in the form of EEG and by EEG graph, system analyze automated result in the form of Experiential Knowledge, Primary processing, Encoding, Emotional Response, Activation Suppression, Inattention. Test procedure proceeds at about 45 minutes to 1 hour for per person per set of audio probes. During test person need not to answer to particular probe. Person have to seat quietly while audio probes presentation. Probes are not full question it's just short sentence which are pre-recorded in BEOS system. BEOS is known as (N.S.S) Neuro signature system.

\section{Variable:}

1. BEOS examine consider as independent variable.

2. Result (Scores) of BEOS is Dependent variable.

\section{Data analysis:}

BEOS auto analyzed result shows various digital values of EK, Encoding, Inattention etc.., Which counted in percentage value.

Neuropsychological assessment of the suspect

\begin{tabular}{|c|c|c|c|c|c|}
\hline & Set1 & Set2 & \begin{tabular}{|l|} 
Set3 \\
\end{tabular} & Total Probes & $\begin{array}{l}\text { \% of Neuro- } \\
\text { Psy awareness }\end{array}$ \\
\hline $\begin{array}{lll}\text { Suspect } & \text { case } & (1) \\
15 / B / 24 & & \end{array}$ & $\begin{array}{l}\text { Total :129 } \\
\text { Probes } \\
\text { presented }\end{array}$ & \begin{tabular}{|l|} 
Total :133 \\
Probes \\
presented
\end{tabular} & & 262 & - \\
\hline $\begin{array}{l}\text { Experiential } \\
\text { Knowledge (EK) }\end{array}$ & 15 & 17 & Nil & 32 & $12.21 \%$ \\
\hline $\begin{array}{l}\text { Primary } \\
\text { (PP) }\end{array}$ & 37 & 42 & - & 79 & $30.15 \%$ \\
\hline Encoding (EN) & 71 & 73 & - & 144 & $54.96 \%$ \\
\hline $\begin{array}{l}\text { Emotional Response } \\
\text { (ER) }\end{array}$ & $\mathbf{0}$ & $\mathbf{0}$ & - & 00 & $00.00 \%$ \\
\hline
\end{tabular}


Neuro- Psychological Assessment of the Suspect by Applying Brain Electrical Oscillation Signature (BEOS) Profiling Test to Verify BEOS Principle

\begin{tabular}{|c|c|c|c|c|c|}
\hline Inattention (IN) & 05 & $\mathbf{0}$ & - & 05 & $\begin{array}{ll}1.90 \% \\
\text { counted }\end{array}$ not \\
\hline $\begin{array}{l}\text { Activation } \\
\text { Suppression (AS) }\end{array}$ & 01 & 01 & - & 02 & $0.76 \%$ \\
\hline \multicolumn{4}{|c|}{$\begin{array}{l}\text { Total Percentage of Neuro-psychological assessment of } \\
\text { awareness during whole test }\end{array}$} & & $98.09 \%$ \\
\hline $\begin{array}{l}\text { Suspect } \text { case }(2) \\
15 / B / 24\end{array}$ & \begin{tabular}{|l|} 
Total :132 \\
Probes \\
presented
\end{tabular} & \begin{tabular}{|l|} 
Total :118 \\
Probes \\
presented
\end{tabular} & - & 250 & \\
\hline $\begin{array}{l}\text { Experiential } \\
\text { Knowledge (EK) }\end{array}$ & 23 & 06 & - & 29 & $11.6 \%$ \\
\hline $\begin{array}{l}\text { Primary Processing } \\
\text { (PP) }\end{array}$ & 34 & 36 & - & 70 & $25.0 \%$ \\
\hline Encoding (EN) & 64 & 69 & - & 133 & $53.2 \%$ \\
\hline $\begin{array}{l}\text { Emotional Response } \\
\text { (ER) }\end{array}$ & 04 & 03 & - & 07 & $2.8 \%$ \\
\hline Inattention (IN) & 04 & 01 & - & 05 & $\begin{array}{l}2.0 \% \\
\text { not counted }\end{array}$ \\
\hline $\begin{array}{l}\text { Activation } \\
\text { Suppression (AS) }\end{array}$ & 03 & 03 & - & 06 & $2.4 \%$ \\
\hline \multicolumn{4}{|c|}{$\begin{array}{l}\text { Total Percentage of Neuro-psychological assessment of } \\
\text { awareness during whole test }\end{array}$} & & $95 \%$ \\
\hline $\begin{array}{lll}\text { Suspect } & \text { case } & (3) \\
15 / B / 24 & & \end{array}$ & \begin{tabular}{|l|} 
Total $: 230$ \\
Probes \\
presented \\
\end{tabular} & \begin{tabular}{|l|} 
Total :196 \\
Probes \\
presented \\
\end{tabular} & - & 426 & \\
\hline $\begin{array}{l}\text { Experiential } \\
\text { Knowledge (EK) }\end{array}$ & 17 & 32 & - & 49 & $11.50 \%$ \\
\hline $\begin{array}{l}\text { Primary Processing } \\
\text { (PP) }\end{array}$ & 65 & 68 & - & 133 & $31.22 \%$ \\
\hline Encoding (EN) & 141 & 84 & - & 225 & $52.81 \%$ \\
\hline $\begin{array}{l}\text { Emotional Response } \\
\text { (ER) }\end{array}$ & 01 & $\mathbf{0}$ & - & 01 & $0.23 \%$ \\
\hline Inattention (IN) & 05 & 02 & - & 07 & $\begin{array}{l}1.64 \% \\
\text { not counted }\end{array}$ \\
\hline $\begin{array}{l}\text { Activation } \\
\text { Suppression (AS) }\end{array}$ & 01 & 10 & - & 11 & $2.58 \%$ \\
\hline \multicolumn{4}{|c|}{$\begin{array}{l}\text { Total Percentage of Neuro-psychological assessment of } \\
\text { awareness during whole test }\end{array}$} & & $98.35 \%$ \\
\hline $\begin{array}{l}\text { Suspect case (4) } \\
15 / B / 28\end{array}$ & \begin{tabular}{|l|} 
Total :154 \\
Probes \\
presented \\
\end{tabular} & \begin{tabular}{|l|} 
Total : 177 \\
Probes \\
presented \\
\end{tabular} & \begin{tabular}{|l|} 
Total:151 \\
Probes \\
presented \\
\end{tabular} & 482 & \\
\hline $\begin{array}{l}\text { Experiential } \\
\text { Knowledge (EK) }\end{array}$ & 15 & 23 & 12 & 50 & $10.37 \%$ \\
\hline $\begin{array}{l}\text { Primary Processing } \\
\text { (PP) }\end{array}$ & 49 & 60 & 38 & 147 & $30.49 \%$ \\
\hline
\end{tabular}


Neuro- Psychological Assessment of the Suspect by Applying Brain Electrical Oscillation Signature (BEOS) Profiling Test to Verify BEOS Principle

\begin{tabular}{|l|l|l|l|l|l|}
\hline Encoding (EN) & 83 & 82 & 91 & 256 & $53.11 \%$ \\
\hline $\begin{array}{l}\text { Emotional Response } \\
\text { (ER) }\end{array}$ & 02 & 03 & 02 & 07 & $1.45 \%$ \\
\hline Inattention (IN) & 01 & 06 & 05 & 12 & $\begin{array}{l}2.48 \% \\
\text { not counted }\end{array}$ \\
\hline $\begin{array}{l}\text { Activation } \\
\text { Suppression (AS) }\end{array}$ & 04 & 03 & 03 & 10 & $2.07 \%$ \\
\hline $\begin{array}{l}\text { Total Percentage of Neuro-psychological assessment of } \\
\text { awareness during whole test }\end{array}$ & 1420 & $\mathbf{9 7 . 5 1 \%}$ \\
\hline
\end{tabular}

\section{RESULT AND DISCUSSION}

1. Case no:1= Total percentage (\%) of neuro-psychological awareness is : $\mathbf{9 8 . 0 9} \%$.

2. Case no:2= Total percentage $(\%)$ of neuro-psychological awareness is : $\mathbf{9 5 . 0 0} \%$.

3. Case no:3= Total percentage (\%) of neuro-psychological awareness is : $\mathbf{9 8 . 3 5} \%$.

4. Case no:4= Total percentage (\%) of neuro-psychological awareness is : $\mathbf{9 7 . 5 1} \%$.

On the basis of above percentile neuro-psychological assessment analyzed. It is clear that all four people were above $95.00 \%$ aware during their BEOS test. While remaining percentage counted as artifact, Inattention etc.

\section{CONCLUSION}

Here in this research first $\mathrm{HO}$ is = There will be no significant difference in neuro-psychological assessment of BEOS result like; primary processing, experiential knowledge, encoding, emotional response, activation suppression. These $\mathrm{HO}$ is rejected because in different criteria of BEOS automated analysis result shows percentile variation in primary processing, experiential knowledge, encoding, emotional response, activation suppression.

Second $\mathrm{H} / \mathrm{O}=\mathrm{BEOS}$ is based on the principles of neuro-psychology which is base less principle. These HO is rejected because EEG cap attached to a person and case related probes were presented during this procedure then suspect were aware in relevant, general neutral probes and neutral probes. All four person's neurological and psychological criteria like: primary processing, experiential knowledge, encoding, emotional response, activation suppression, were counted together so it shows above $\mathbf{9 5 . 0 0} \mathbf{\%}$ all four persons were neuro-psychologically aware during the BEOS test.

NABL Scope of Accreditation report (year: 2014) mentioned that BEOS test is for verification of veracity of statement of the suspect, accused, witness, complainant and victim. BEOS instrument's range of testing and limits of detection is .99 (200). This research supports NABL report of 'BEOS range testing limits of detection'. Hence, the BEOS is bases on the principles of neuro-psychology which depict valid and true by this research. 


\section{REFERENCE:}

Dawson, G.D. (1947) Central responses to electrical stimulation of peripheral nerve in man. J. Neurol. Neurosurg.Psychiatry. 10.137-140.

Dr. S.L Vaya (2005-2007), Additional Director and Principal investigator of National Resource center, Forensic Psychology DFS Gandhinagar, Gujarat, India. Book referred: Forensic Psychology's National Resource center (2013).

Goff, W.R. (1947) Human average evoked potentials: Procedures for stimulating and recording. In: Thompson, R.F and Patterson, M.M (Eds) Bioelectric Recording Techniques, Part B. Electroencephalography and Human Brain Potentials. Academic Pess. New York. 101156.

Hume, A.G \& Cant, B.R (1978) Conduction time in central somatosensory pathways in man. Electroencephalogr. Clin. Neurophysiol. 45:361-375.

Lueders, H., Andrish, J., Gurd, A., Garry, W. \& Klem, G. (1981) Origin of far-field sub cortical potentials evoked by stimulation of the posterior tibial nerve. Electroencephalograph. Clin. Neurophysiol. 52:336-344.

Mukundan C.R (2007) Brain Experience; Neuroexperiential perspective of brain-mind. Atlantic publishers and distributors, India Pvt.Ltd.

Mukundan, C.R. (1985) NIMHANS "Middle latency components of evoked potential responses in schizophrenics". Bio.Psychiatry.

Tsumoto, T., Hirose, N., Nonaka, S. \& Takahashi, M. (1972) Analysis of somatosensory evoked potentials to lateral popliteal nerve stimulation in man. Electroencephalograph. Clin. Neurophysiol. 33:379-388.

\section{ACKNOWLEDGEMENT}

I would like to express gratitude to my supervisor Dr. D. J Panchal for introducing me to the topic and for the heartfelt support and encouragement. Furthermore, I would like to thank Mr. H. T Sanghvi Sir, Deputy Director DFS (Directorate of Forensic Sciences) Gandhinagar for his useful comments and remarks. The Department of Psychology has provided the support and equipment that are mandatory to produce and complete my Research work. In my daily work i have been blessed with a friendly and cheerful colleagues and Supervisors \{ Smt. A. D Shukla (Assistant Director, Forensic Psychology Division, DFS and H. R Shah Madam (Scientific Officer, Forensic Psychology division, DFS) \}. I will forever be grateful for all your love and help. Finally, I want to thank my family members and relatives for supporting me throughout all my studies at University and helping me to reach at this level. 